\title{
STUDENT LOANS AND SEED-FUNDS: ASSESSING THE NEED FOR EARLY-CAREER FINANCIAL PLANNING IN URBAN INDIA
}

\author{
Soham Mohta \\ Step by Step School
}

DOI: 10.46609/IJSSER.2020.v05i09.021 URL: https://doi.org/10.46609/IJSSER.2020.v05i09.021

\begin{abstract}
Given the turbulent state of the economy and the pervasive issues of unemployment and underemployment, financial planning for early career professionals has become essential and integral especially in urban India. However, access to financial planning services, the burden of student loans, lack of well paying job opportunities and a lack of seed funding opportunities all exacerbate the issue. In addition, women are often unable to have the requisite savings due to lack of financial literacy and social restrictions. This paper will examine the issues pertaining to financial planning for early career professionals, and the largest obstacles that have prevented an equitable solution from arising. The paper will propose policy recommendations as well as a rights based approach to education and loans, to better tackle the issue and ensure the youth of India are able to save, consume and create jobs themselves.
\end{abstract}

Keywords: Seed-Fund, Finance, Policy, Education, Loan.

\section{Introduction}

With the increasing number of young people entering the workforce and the increased participation of other population groups such as women, there is a sharp increase in the number of early career professionals, especially in a developing country such as India where the proportion of youth entering the workforce is increasing by the year. This has led to more migration to urban regions, as well as increased competition for an increasingly limited number of jobs. Consequently, qualification requirements for such jobs have become more stringent, and the cost of living has increased in urban areas without a requisite increase in wages.

With these issues has come an increase in the need for awareness, schemes and initiatives on early career financial planning for the long term, to cope with the rising costs of living and to make the most out of one's educational qualifications and employment opportunities. This is often a challenge for young early career professionals, since one may not be aware of future 


\section{International Journal of Social Science and Economic Research}

ISSN: $2455-8834$

Volume:05, Issue:09 "September 2020"

opportunities and timelines, and therefore, aptly planning for the long term could be difficult (Nandan, 2017). Common measures to begin inculcating savings at an early stage have been to gain interest from savings accounts, or put earnings into fixed deposits. For those from urban areas, the services of financial planners have become increasingly popular as well (Nandan, 2017). More early career professionals are finding a need to fulfil short term needs sufficiently, which requires higher liquidity. To this end, instruments such as short term debt funds and arbitrage funds are becoming popular modes of investment (Nandan, 2017). For long term needs, investing in equity mutual funds are also popular (Nandan, 2017).

For early career professionals who are women, the need for financial planning is even more important than for men. It is documented in several cases that women earn $20 \%$ less than men on average, globally (Siva, 2019). Therefore, for both short term and long term savings, women have lesser lifetime earnings (Siva, 2019). In addition, women would be more likely to take career breaks which would lead to a loss in salary, and reduce regular savings, affecting investments early on in their careers (Siva, 2019).

This paper will elaborate further upon the various challenges that exist with respect to financial planning for early career professionals, and the hurdles that could be cleared with better policy measures targeted towards creating awareness and reducing their early financial burdens. The paper will critically examine the situation with higher education and the available financial systems, and propose better policies to remedy the increasingly arduous financial situations that early career professionals are finding themselves in.

\section{Background}

The term "early career professional" is often used to indicate a generation of professionals that demonstrates the potential to succeed established professionals and leaders (Kulkarni et al, 2018). These are typically professionals who have entered the workforce directly out of colleges and universities (Kulkarni, 2016). Several studies have documented the relationship between education, occupational stability and income (United Nations, n.d). There is no doubt that education enables upward socioeconomic mobility and is a key to escaping poverty (United Nations, n.d). With higher education comes higher income. However, increasing levels of income inequality as well as economic turbulence have led to a situation where early career professionals often struggle to get employment despite their qualifications (Kurup, 2019).

It has further been documented that India's unemployment is rapidly rising, for nearly two thirds of Indians who are of working age, that is between the ages of 15 and 64 (Kurup, 2019). This unemployment rate rises even as the gross enrolment ration in higher education has risen from 19.4 to 25.8 percent between 2010 and 2018 (Kurup, 2019). This is one reason why the young, 


\section{International Journal of Social Science and Economic Research}

ISSN: $2455-8834$

Volume:05, Issue:09 "September 2020"

15 to 26 years of age, are over-represented in unemployment figures - as they have invested heavily in higher education, many would rather wait for a formal job than enter informal, lowpaying employment (Kurup, 2019). This further adds to the burden of overqualified, unemployed and under employed early career professionals.

This further exacerbates the issue of debt among early career professionals, in large part due to student and education loans. In India, the concept of education loans began in 1962 with the National Loans Scholarship Scheme (Manickam, 2019). This was replaced with the current system of commercial bank driven loans. Lower income students have more difficulty paying back student debt, than those who take larger loans (Manickam, 2019). It has been documented that there is an increasing amount of student debt across India, with a higher debt-service ratio and loan default rates, due to the fact that well paying jobs are not available post the graduation of early career professionals (Manickam, 2019). With more jobs lost in the future due to economic turbulence and automation, this issue will only be increased and lead to more systemic and structural issues with respect to accessibility to education, opportunities and struggles in financial planning, which will lead to long term ramifications for retirement and emergency savings (Manickam, 2019; Kurup, 2019). Several activists have called for reform to the commercially driven system of student debt in India.

To encourage startups and young entrepreneurs, the government has implemented the Startup India program. While the assistance offered varies from state to state, several states offer seed funding to young startups and social entrepreneurs with a purpose (Startup India, n.d). There are several benefits available to startups including tax incentives, expedited regulatory processes and subsidized costs of incorporation, among many others (Startup India, n.d). There is currently a proposal from the Department for Promotion of Industry and Internal Trade (DPIIT), which will soon approach the Cabinet with a proposal to create a National seed fund and launch a credit guarantee scheme to help budding entrepreneurs and startups (Suneja, 2020). The National Seed Fund seeks to support ideation and development of early stage startups whereas the credit guarantee scheme will enable startups to raise easier loans (Suneja, 2020).

While such measures are steps in the right direction, it remains that the systemic issues of unemployment are unaddressed and has led to a large population of overqualified and unemployed early career professionals in urban areas. The following section will elaborate on measures that can be taken to ease the burdens of financial planning and issues that policy makers must place a focus on for a more sustainable environment of debt, savings, and consumption. 


\section{International Journal of Social Science and Economic Research}

ISSN: 2455-8834

Volume:05, Issue:09 "September 2020"

\section{Discussion}

The government and policy makers must tailor schemes and incentives towards early career professionals, particularly towards lower income and lesser educated groups, as well as women and other minority populations. There is a need to implement better methods of performing effective early-career financial planning and spread awareness regarding the same, to ensure proper savings alongside debt management (Siva, 2019; Kulkarni, 2016). To this end, one of the first key measures policy measures must take is to subsidize student loans and reduce interest rates on loans. There must be a more systemic and nuanced approach of understanding the effects of student loans on early-career professionals, rather than placing a focus on individual success stories of loans improving quality of life and allowing those individuals to access better career opportunities (Manickam, 2019). Better financial planning and awareness would come with approaching the unemployment crisis as a structural issues, with the government examining the issue in each sector, further integrating early career professionals in the service sector which contributes to more than half the Indian economy (Manickam, 2019; Kurup, 2019).

The myth of an increase and abundance in high paying jobs for early career professionals must be done away with. On a similar footing as the startup India initiative, policy makers can implement financial literacy programs tailored towards different sections of society. Financially literate individuals do better at budgeting, saving money, controlling spending, handling debt, participating in financial markets, planning for retirement and successfully accumulating wealth (Siva, 2019).

While approaching the issue of a lack of financial planning in a structural and systemic fashion, the issues mentioned in this paper must be contextualized with respect to expensive costs of privatized and high-quality education and the only limited spots for state-funded education institutes. In this context, it is pertinent to note that within the current regulatory framework, higher education is seen as a matter of privilege and not a right, as is the case with primary and secondary education (Manickam, 2019; Mukherjee, 2018). Due to such a conception, educational loans also become a matter of privilege and not a right, as a natural consequence (Mukherjee, 2018). This leads to a situation wherein there are limited slots for state funded institutions, but an increase in loans and defaults on loans for those who do not have an option but to opt for private educational institutions.

The concept prevails that banks must exercise proper financial judgement even while allocating education loans, even if the borrower appears to be deserving and brilliant (Mukherjee, 2018). Therefore, several other factors could influence the borrowing credibility of early career professionals, such as their caste, their gender, and other factors that are divorced from merit (Manickam, 2019). Therefore, there is a need to re-conceptualize the concept of higher 


\section{International Journal of Social Science and Economic Research}

ISSN: $2455-8834$

Volume:05, Issue:09 "September 2020"

education, with subsidies on student loans as well as regulations to make the process of obtaining scholarships, loans, and seats in both private and government institutions more equitable. In turn, this will benefit early career professionals with their financial planning, in conjunction with financial literacy programs.

There is also a need to support early career professionals who wish to create their own employment, which will also offset the issue of unemployment and underemployment, since entrepreneurs will also create jobs for others. To this end, implementing schemes for seedfunding and better government provisions for entrepreneurship development will help with financial planning on a micro level, as well as help the economy on a macro level. Several schemes are available, such as MSME Market Development Assistance, The Women Entrepreneurship Platform launched by the NITI Aayog, micro financing for NGOs and self-help groups, the Pradhan Mantri Mudra Yojana, among several others (Karelia, 2020; Khatri, 2020). The implementation of the national seed fund may assist in making the process more centralized, and help a wider variety of young entrepreneurs and early career professionals (Khatri, 2020; Suneja, 2020). It remains to be seen whether the seed fund would help the economy and improve the burdens upon early career professionals with respect to their financial planning (Khatri, 2020).

\section{Conclusion}

From high student loans to a lack of seed funding, as well as societal norms that prevent the entry of women and others to the workplace, early career professionals struggle to plan financially for both the short and long term. There must be policies which cater specifically to such professionals, as well as policies to help them offset the costs of their education. There must be efforts to improve the educational ecosystem, for sustainable and affordable options, doing away with the fallacy that there will be jobs available upon university graduation (Kulkarni, 2016).

As the world economy has entered into unsettling times with the COVID-19 pandemic, the government must rethink the new nature of work to better accommodate the financial needs of early career professionals. Reports by the ILO, World Bank and World Economic Forum all advocate various forms of "skilling," many of which fall within the realm of higher education (Manickam, 2019). Moving away from a heavily privatized and loan based education system would be conducive to creating new skills for early career professionals to better integrate with the future of work and improving their financial situation.

While the services of financial planners are useful for early career professionals, it is crucial that their services be made more accessible and not only available to a select demographic of 


\section{International Journal of Social Science and Economic Research}

ISSN: $2455-8834$

Volume:05, Issue:09 "September 2020"

professionals who have the luxury of affording the same. Educational institutions can develop courses and provide resources and establish formal mentorship programs internally (Kulkarni, 2016). Alternatively, they can partner or liaise with organizations that already offer high-quality educational resources and training programs on this subject (Kulkarni, 2016). If educational institutions prepared their graduates for financial planning, it would better help to manage expectations with respect to a turbulent economy. In addition, there is a need for a rights based approach to education as well as access to finances for higher education, as well as efforts to target women and marginalized communities of early career professionals (Manickam, 2019; Siva, 2019).

Seed funding programs must also be catered specifically to early career professionals who have graduated from higher educational institutions, along with others. Only if such professionals are targeted specifically can the issue of financial planning be effectively tackled. Financial literacy programs on systematic investment plans, mutual funds, and other instruments for short and long term savings must be implemented both by the government and by the private sector organizations, as increased savings and consumption will only benefit the economy for all.

\section{References}

Karelia, G, (12 March 2020), 'Starting Your Own Business? 10 Govt Schemes Every Entrepreneur Should Know', The Better India, https://www.thebetterindia.com/219696/indiagovernment-schemes-entrepreneurs-startup-women-ngo-msme-fundinggop94/\#: :text=Atal\%20Incubation\%20Centre\%20(AIC), covering\%20their\%20capital\%20opera tional $\% 20 \mathrm{costs} . \&$ text $=$ The $\% 20 \mathrm{AICs} \% 20 \mathrm{can} \% 20 \mathrm{be} \% 20 \mathrm{set}$, Private $\% 20$ Partnership $\% 20(\mathrm{PPP}) \% 2$ 0mode.

Khatri, B, (1 Feb 2020), 'Union Budget 2020: Govt To Set Up Seed Fund To Support Early Stage Startups', Inc42, https://inc42.com/buzz/budget-2020-govt-to-set-up-seed-fund-to-supportearly-stage-startups/

Kulkarni, K, et al, (2018), 'Early career professionals: A challenging road', Research and Practice in Thrombosis and Haemostasis, Vol.2, Issue 1, https://onlinelibrary.wiley.com/doi/full/10.1002/rth2.12070

Kulkarni, S, (27 September 2016), 'The challenges and needs of early career professionals: An overview of SSP's survey', Editage Insights, https://www.editage.com/insights/the-challengesand-needs-of-early-career-professionals-an-overview-of-ssps-survey?refer=scroll-to-1$\underline{\text { article \&refer-type }=\text { article }}$ 
International Journal of Social Science and Economic Research

ISSN: 2455-8834

Volume:05, Issue:09 "September 2020"

Kurup, D, (17 May 2019), 'Work undone: How India fails its young job seekers', Al Jazeera, https://www.aljazeera.com/news/2019/05/work-undone-india-fails-young-job-seekers$\underline{190503111153484 . h t m l}$

Manickam, K, (27 November 2019), 'The Dangerous Myth of the Student Loan', The Wire, https://thewire.in/education/student-loan-jnu-protests

Mukherjee, B, (22 March 2018), 'Education Loans Challenges and Opportunities', Stoodnt, https://www.stoodnt.com/blog/education-loans-challenges-and-

opportunities/\#: :text=Rising\%20incidents $\% 20$ of $\% 20$ failing\%20in,and\%20a\%20third\%20party

\%20guarantor.

Nandan, K, (24 April 2017), 'In early career, financial plans can also be for short-term goals', Livemint, https://www.livemint.com/Money/CTCqEmtYZHrctIYMijYZXP/In-early-careerfinancial-plans-can-also-be-for-shortterm.html

Siva, M, (3 November 2019), 'Why women need financial planning', The Hindu, https://www.thehindu.com/business/why-women-need-financial-planning/article29865628.ece

Startup India, (n.d), 'Seed Funding Support', https://www.startupindia.gov.in/content/sih/en/compendium_of_good_practices/seedfundingsup port.html\#: :text=A\%20seed\%20grant\%20of\%20up,a\%20period\%20of\%2010\%20years.

Suneja, K, (25 May 2020), 'DPIIT to seek nod for startup credit scheme, seed fund', The Economic Times https://economictimes.indiatimes.com/small-biz/startups/newsbuzz/dpiit-toseek-nod-for-startup-credit-scheme-seed fund/articleshow/75961701.cms?utm_source=contentofinterest\&utm_medium=text\&utm_campa ign=cppst

United Nations, (n.d), 'Sustainable Development Goals: Quality Education', https://www.un.org/sustainabledevelopment/education/ 